\title{
A importância da reciclagem do cobre na sustentabilidade de carros elétricos
}

\section{The importance of copper recycling in the sustainability of electric cars}

\author{
Emerson Paulino dos Reis ${ }^{1}$, Glaucia Katiuscia Ferreira ${ }^{1}$, Natan Felipe Silva ${ }^{1}$, Daniel \\ Enrique Castro ${ }^{2}$
}

${ }^{1}$ Centro Universitário de Formiga-UNIFOR-MG. Formiga, Minas Gerais, Brasil.

${ }^{2}$ Centro Federal de Educação Tecnológica de Minas Gerias- CEFET-MG. Belo Horizonte, Minas Gerais, Brasil.

\begin{abstract}
Resumo
Introdução: O carro elétrico surgiu como alternativa de reduzir a emissão de poluentes e a dependência de combustíveis fósseis dos veículos de combustão interna. Porém as comparações são feitas, em geral, em uma única fase do ciclo de vida do veículo: a da vida útil, fazendo-se necessário desenvolver estudos mais profundos em todas as fases do ciclo de vida, que vai da extração dos minerais até o processo de reciclagem final do veículo, evidenciando e quantificando todos os impactos ambientais. Objetivo: Este trabalho tem por objetivo avaliar o impacto energético atrelado ao cobre utilizado na fabricação do carro elétrico em dois cenários: um utilizando o cobre a partir da reciclagem de veículos e outro utilizando os processos convencionais de mineração praticados atualmente. Metodologia: Para o desenvolvimento do trabalho, pesquisou-se a tendência de produção de carro elétrico no mundo, o consumo de cobre nos carros elétricos, reservas declaradas de cobre no mundo, processo de reciclagem de veículos e de cobre, além da análise do ciclo de vida do cobre. Resultados: Os resultados observados neste estudo mostram que a reciclagem do cobre nos veículos elétricos pode atingir uma economia média de 3,5 milhões de MWh/ano, o equivalente à capacidade produtiva de energia elétrica de uma usina termoelétrica de grande porte no Brasil. Isso significa que a reciclagem do cobre poderá poupar a construção de uma usina termoelétrica por ano no Brasil. Conclusão: Observou-se no estudo que, com a escassez cada vez maior de recursos naturais, este artigo desperta e fomenta a necessidade de aprofundar a pesquisa relacionada com os impactos ambientais dos veículos elétricos.
\end{abstract}

Palavras chaves: Carro elétrico; Análise do ciclo de vida; Combustíveis fósseis.

Autora correspondente:

Glaucia Katiuscia Ferreira

Endereço: Rua Zeca Francisco, 681, Chico Miranda,

CEP 35590-000. Lagoa da Prata (MG), Brasil.

E-mail: glauciakatiuscia2014@gmail.com
Recebido em: 21/01/2019

Revisado em: 09/03/2019

Aceito em: 02/08/2019

Publicado em: 30/09/2019 


\section{Abstract}

Introduction: The electric car arose as an alternative to reducing the emission of pollutants and the dependence of fossil fuels on internal combustion vehicles. However, the comparisons are generally made in a single phase of the vehicle's life cycle: the useful life, making it necessary to develop deeper studies in all phases of the life cycle, from the extraction of minerals until the final recycling process of the vehicle, showing and quantifying all the environmental impacts. Objective: The objective of this study is to evaluate the energy impact of copper used in the production of the electric car in two scenarios: one using copper from the recycling of vehicles and the other using the conventional mining processes practiced today. Methodology: For the development of the work, we investigated the trend of electric car production in the world, the consumption of copper in electric cars, declared reserves of copper in the world, process of vehicle recycling and copper, in addition to the analysis of the cycle of copper life. Results: The results observed in this study show that the recycling of copper in electric vehicles can achieve an average economy of 3.5 million $M W h$ / year, equivalent to the productive capacity of electric power of a large thermoelectric power plant in Brazil. This means that recycling copper may save the construction of one thermoelectric plant per year in Brazil.

Conclusion: It was observed in the study that with the increasing scarcity of natural resources, this article awakens and fosters the need to deepen the research related to the environmental impacts of electric vehicles.

Keywords: Electric car; Life cycle analysis; fossil fuels.

\section{Introdução}

Há uma ligação entre a história das baterias e a dos automóveis ${ }^{1}$. A cronologia do início do desenvolvimento das baterias até a criação do primeiro carro elétrico é apresentada na TABELA 1 adaptada do estudo de Barran ${ }^{1}$ :

\section{TABELA 1. Principais fatos sobre o carro elétrico}

\begin{tabular}{cc}
\hline Ano & Principais fatos sobre o carro elétrico \\
\hline 1839 & Construção do primeiro veículo com motor elétrico. \\
1842 & Construção do primeiro veículo elétrico de bateria não recarregável. \\
1859 & Construção da primeira bateria de chumbo e ácido. \\
1897 & Auge da produção e comercialização de carros elétricos. \\
1901 & Criação do primeiro carro a combustão interna pela empresa alemã Mercedes Benz. \\
1940 & A produção dos veículos foi impulsionada a fim de diminuir a poluição nas grandes cidades. \\
\hline
\end{tabular}

Atualmente existem três categorias de automóveis elétricos: à bateria, os híbridos convencionais e os híbridos recarregáveis ${ }^{2}$, porém a produção de veículos de combustão interna prevalece atualmente e é consolidada em todo o mundo. Ela emprega milhares de pessoas direta e indiretamente e é um mercado que gera muitas divisas para os países, não apenas pela simples venda dos veículos de combustão interna, mas pela cadeia 
produtiva que envolve esse mercado como: a) a extração de minerais tais como ferro, cobre, alumínio entre outros; b) as indústrias de transformação primária como siderúrgicas e fundições que fornecem matérias primas para as fábricas de autopeças; c) a extração e beneficiamento da borracha para fabricação de peças e pneus; d) a extração do petróleo e seus processos de refino para obtenção de combustível, lubrificantes e plásticos; e) a construção de estradas e pavimentação de ruas; f) a venda de autopeças para manutenção da frota circulante de veículos; e g) os serviços de manutenção propriamente dito $^{3}$.

No início de 2018, a frota mundial de veículos elétricos chegou a 2 milhões, o que representa um aumento de $55 \%$ em relação ao mesmo período do ano anterior e a previsão para 2030 é que a quantidade de carros elétricos, no mundo, deve atingir 140 milhões, aproximadamente $10 \%$ da frota total de veículos leves de passageiros $^{4}$. A vida útil desse tipo de veículo está intimamente ligada ao número de ciclos (que é a quantidade de recargas) que a bateria possui mas, geralmente, a longevidade das baterias elétricas é prevista em $10 \operatorname{anos}^{5}$.

Tendo em vista o exposto, o objetivo geral do presente estudo é demostrar as vantagens em termos de eficiência energética no reaproveitamento do cobre para produção de veículos elétricos.

\section{Revisão bibliográfica}

Para a elaboração deste artigo foi realizada uma revisão bibliográfica sobre: a) a história do carro elétrico; b) a produção atual e as tendências mundiais do carro elétrico no mundo; c) o ciclo de vida e vida útil; e) o ciclo de vida do cobre e suas reservas. Por meio dessa revisão, será possível avaliar o impacto energético do carro elétrico ao cobre utilizado em sua produção.

\subsection{ACV - análise do ciclo de vida}

A ACV (análise do ciclo de vida) de um produto deve englobar todo o processo ou sua atividade, quais sejam: extração, processamento de matérias primas, fabricação, transporte e distribuição, uso, reemprego, manutenção, reciclagem, reutilização e disposição final. ${ }^{6}$ O ciclo de vida nada mais é que a história do produto, desde a fase de extração das matérias-primas, passando pela fase de produção, distribuição, consumo e uso, até sua transformação em lixo (tudo aquilo que não é possível reutilizar ou reaproveitar) ou em resíduo (tudo aquilo que se pode reutilizar ou reaproveitar $)^{7}$. A ACV é uma técnica utilizada para avaliar aspectos ambientais e impactos potenciais associados a um produto mediante:

1. A compilação de um inventário de entradas e saídas pertinentes de um sistema de produto;

2. A avaliação dos impactos ambientais potenciais associados a essas entradas e saídas;

3. A interpretação dos resultados das fases de análise de inventário e de avaliação de impactos em relação aos objetivos dos estudos.

A estrutura da análise do ciclo de vida baseia-se na (FIGURA 1).

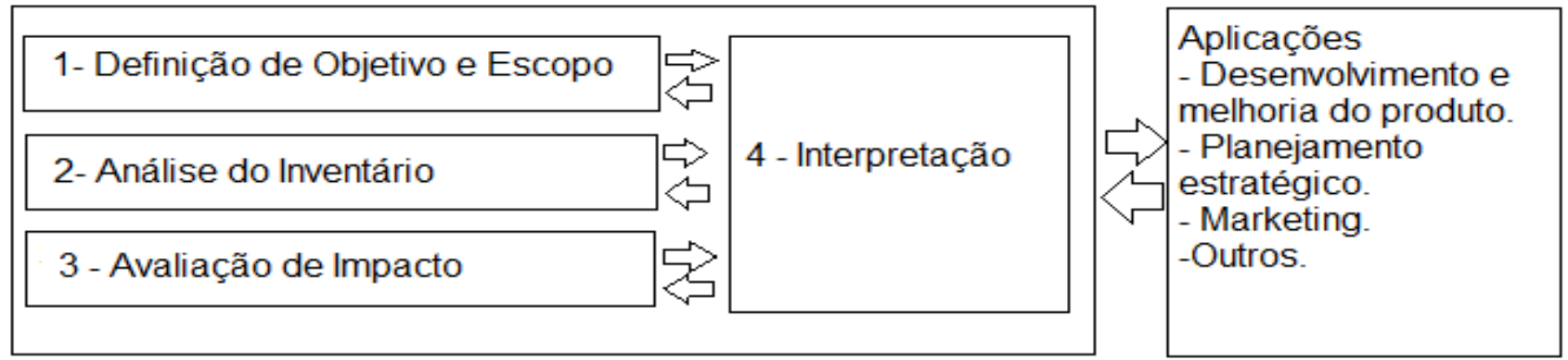

FIGURA 1. Estrutura de análise do ciclo de vida. Fonte: Reis et al ${ }^{7}$ 


\subsection{Produção de cobre e suas reservas}

As reservas mundiais de cobre no ano de 2014 totalizaram em 703 milhões de toneladas e, no Brasil, as reservas brasileiras totalizam em 10.844 milhões de toneladas do minério. Os principais estados brasileiros produtores do minério são: Pará (84,99\%), Goiás (7,92\%), Bahia $(3,79 \%)$ e Alagoas $(2,95 \%)^{9}$. O processamento do cobre, desde a extração até a transformação final, passa pelas etapas de prospecção, pesquisa, mineração, concentração, metalurgia e transformação em produto. Além dessas, é acrescida a reciclagem, processo pelo qual o cobre pode ser reutilizado na sua totalidade ${ }^{10}$, como mostrado na (FIGURA 2).

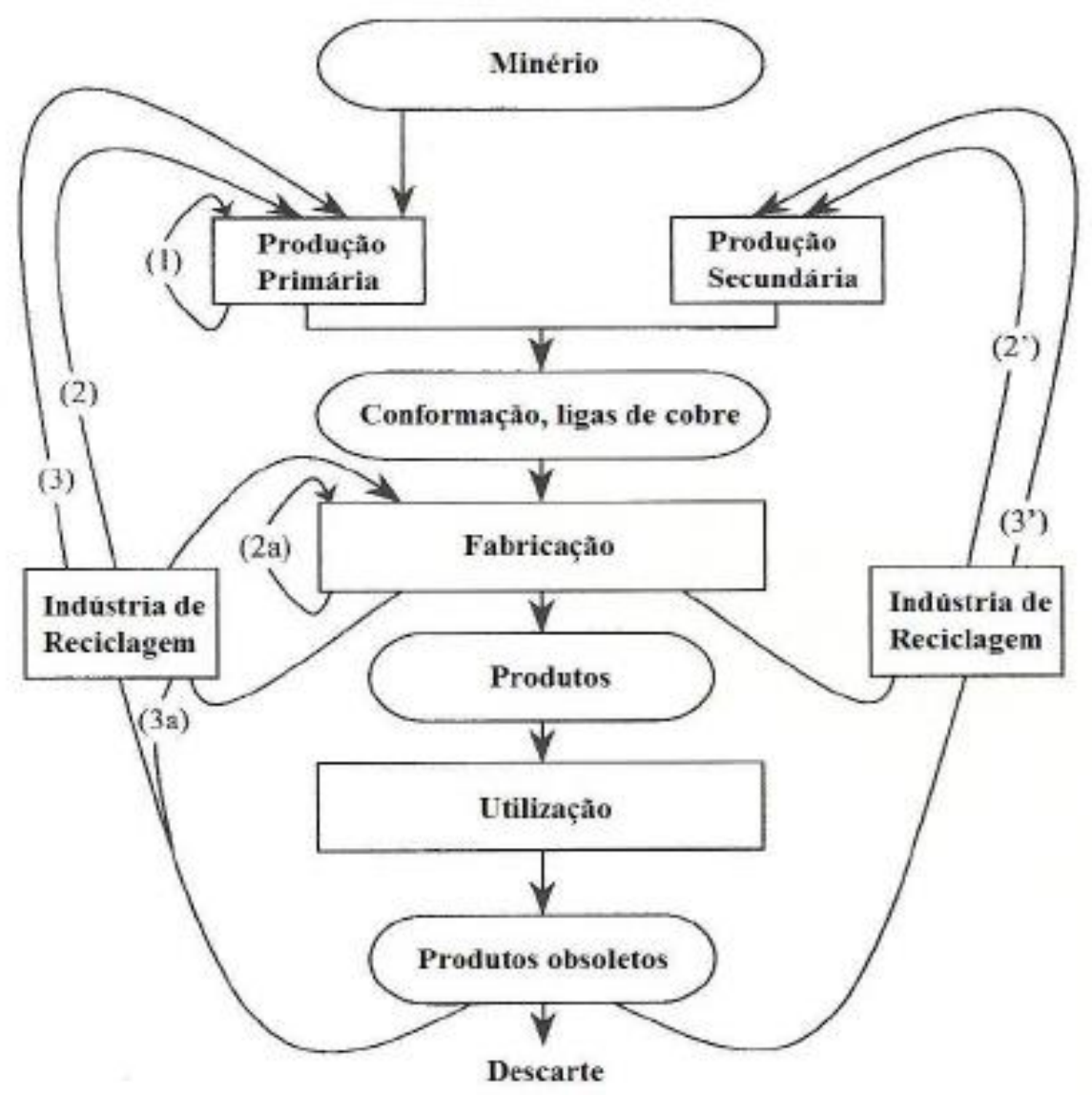

FIGURA 2. Fluxograma reciclagem do cobre. Fonte: Silva ${ }^{10}$.

A reciclagem do cobre gera cerca de $1 / 3$ da produção de cobre mundial ${ }^{10}$. Além disso, $50 \%$ do cobre que chega do mercado por meio de produtos, já foi reciclado alguma vez. A (FIGURA 2) representa a sucata de cobre que é gerada e reaproveitada no próprio processo de produção primária. Os fluxos (2), (2a), (2’) apresentam as sucatas de cobre que são geradas dentro do processo de fabricação de um determinado produto. As principais características dessas sucatas são as ligas de cobre junto a outros elementos. Os fluxos (3), (3a), (3’) apresentam o aproveitamento de cobre nos variados bens de consumos que chegam ao fim de sua vida útil.
Para verificar a quantidade de cobre reciclado no mundo, utilizou-se a taxa de entrada de cobre no mercado, a taxa de coleta de material em fim de vida útil e a taxa de processamento, obtendo uma taxa global de reciclagem de cobre em $46 \%$ com $68 \%$ de eficiência de aproveitamento $^{11}$. Isso mostra a necessidade de contribuir com o aumento na eficiência da reciclagem do cobre.

\subsection{Crescimento da frota de veículos elétricos e o volume de cobre}

A Anfavea aponta que o número de carros elétricos ou híbridos vendidos no Brasil foi de 562, no primeiro 
trimestre de 2017, para 893 no mesmo período, em 2018. Com base nos Registros Nacionais de Veículos Automotores, a Associação divulgou que houve um aumento de 58,9\% na venda de carros elétricos e híbridos $^{12}$. Segundo o Denatran (Departamento Nacional de Transito) existe cerca de 7,120 carros elétricos e híbridos em circulação hoje no Brasil.

Com o aumento da produção de carros elétricos, a utilização de cobre tem aumentado significativamente, devido a sua característica de condução de eletricidade ${ }^{13}$.

Dentro dos VEs e VEHs, o cobre está presente principalmente em chicotes elétricos, nos motores de propulsão e na bateria. Além disso, é encontrado em aplicações tradicionais como equipamentos eletrônicos, acessórios audiovisuais e fios. Isso justifica o fato desses automóveis terem entre 2 e 3 vezes mais cobre do que veículos de combustão comuns, conforme (FIGURA 3).

\section{Cada Nova Geração de Carros Necessita de Mais Fios de Cobre}

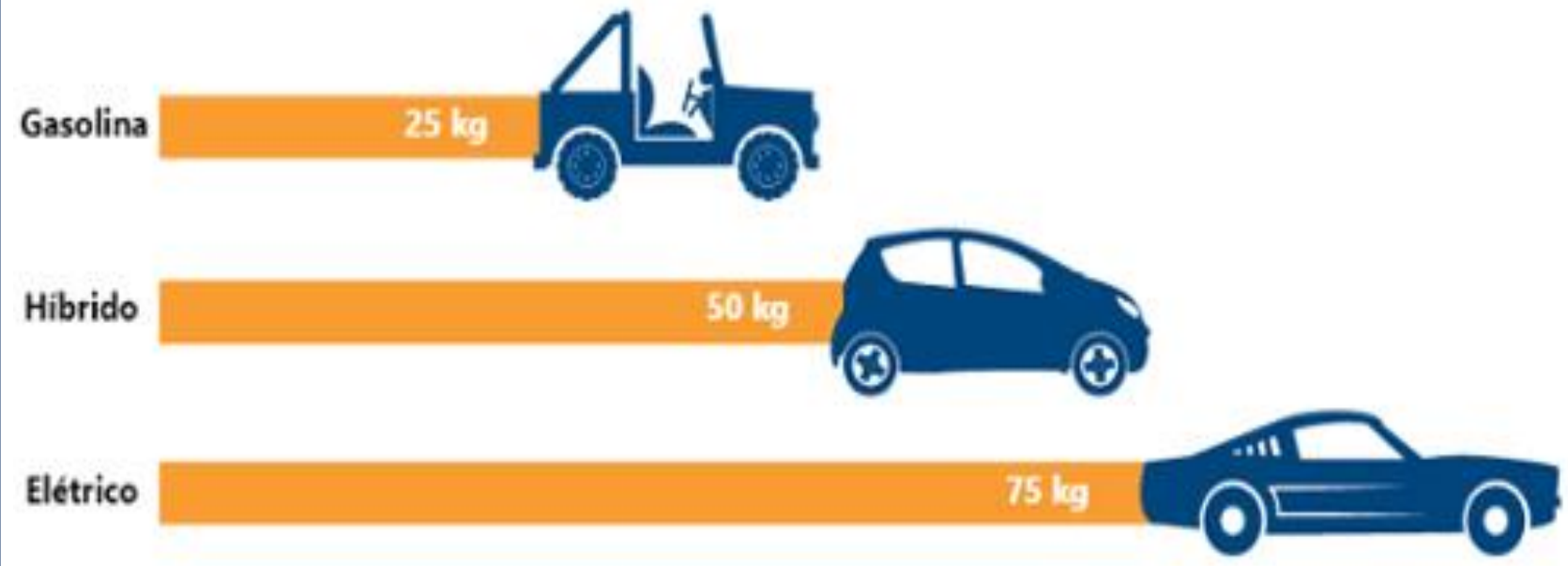

FIGURA 3. Volume do cobre nos carros. Fonte: Uso do carro eletrico ${ }^{13}$.

\section{Metodologia}

A metodologia proposta foi realizar a Análise do Ciclo de Vida do minério cobre considerando a reciclagem de carros elétricos. Os dados utilizados na elaboração dessa etapa foram obtidos mediante pesquisa bibliográfica. A análise do ciclo de vida do cobre tem a finalidade de determinar o consumo energético, a partir do cobre obtido da reciclagem de carros elétricos. O escopo apresentado na (FIGURA 4) representa o limite do sistema para análise do ciclo de vida do minério utilizado em veículos.

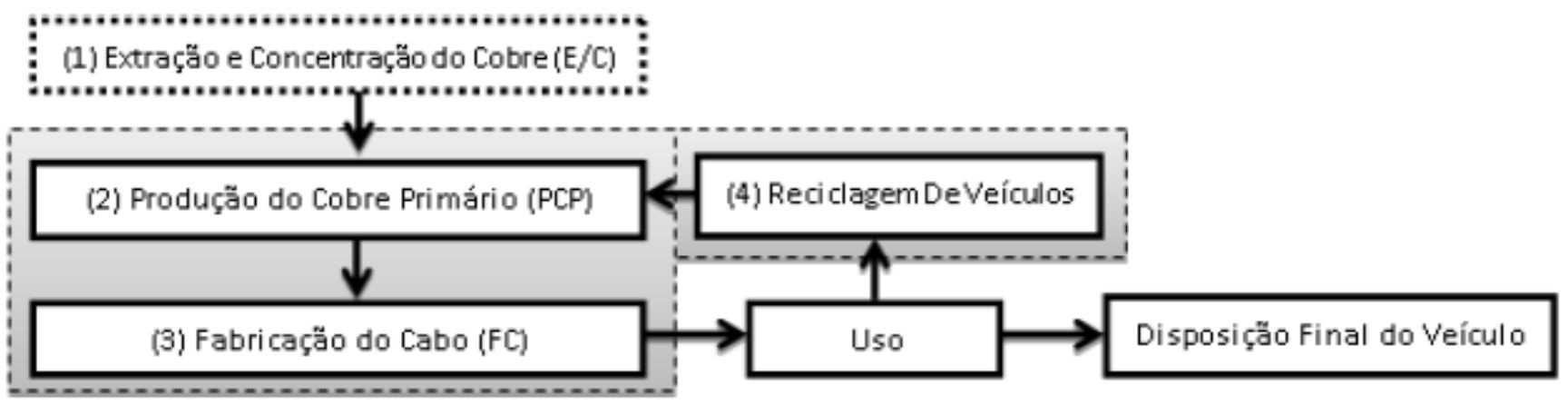

FIGURA 4. Limites do cenário com reciclagem. Fonte: Reis (2015). 


\subsection{Definição do escopo para ACV}

Para os cálculos de consumo de energia elétrica foram considerados os seguintes tópicos: a tendência de produção de carros elétricos no mundo e o consumo do cobre para a fabricação desse tipo de automóvel, as reservas do cobre e o processo de reciclagem do veículo, o processo de reciclagem de veículo e de cobre e o ciclo de vida.

Tendência de produção de carro elétrico no mundo: um estudo recente da FGV (Fundação Getúlio Vargas) mostra que a frota mundial de veículos elétricos e híbridos, no ano de 2017, era de 2 milhões de unidades para passageiros (exclui-se ônibus e motocicletas) ${ }^{14}$. A previsão é de que, até 2020, chegue a 13 milhões e, em 2030, a 140 milhões, ou $10 \%$ da frota total de carros ${ }^{15}$. No Brasil, desde 2011, foram vendidos 5,9 mil carros elétricos e híbridos, dos quais 2.079 neste ano, quase o dobro de 2016.

Consumo de cobre nos carros elétricos: um carro convencional contém aproximadamente $25 \mathrm{~kg}$ de cobre e suas ligas, o que pode variar de acordo com a marca e o modelo ${ }^{16}$. O conteúdo de cobre no carro elétrico varia de $68 \mathrm{~kg}$ a $81 \mathrm{~kg}^{17}$. Isso significa que o consumo desse metal vai mais que dobrar para veículos elétricos.

Reservas declaradas de cobre do mundo: as reservas mundiais de minério de cobre lavráveis registraram, em 2011, um total de 690 milhões de toneladas em metal contido, quantidades $6,9 \%$ superiores as de $2010^{9}$. As reservas brasileiras lavráveis de cobre, em 2011, somaram 11.063 milhões de toneladas de cobre contido, apresentando um aumento de 12,9\% sobre o ano anterior. A produção mundial de concentração de cobre, em metal contido alcançou, em 2011, uma quantidade de 16.035 milhões de toneladas. O mercado mundial do cobre apresentou, em 2011 um déficit de produção frente ao consumo da ordem de 241 mil toneladas.

Processo de reciclagem de veículo e de cobre: o processo de reciclagem dos veículos, segue seis etapas: recepção dos veículos a serem reciclados (ELV's), desmontagem dos ELV's, classificação dos componentes desmontados dos ELV's, fragmentação dos ELV's, reciclagem dos materiais fragmentados de ELV's, reutilização de peças $^{18}$. A reciclagem do cobre pode ocorrer de duas formas: a primeira com sucatas obtidas nas indústrias que manuseiam exclusivamente o cobre. Pode-se obter uma sucata de boa qualidade e alta condutibilidade, e pode ser reciclado pela simples fusão, antes da fundição, para aplicação que se requeira alta pureza de cobre $^{19}$. Em caso de contaminação, será necessário fundi-lo no formato de anodo para que seja purificado eletroliticamente. $\mathrm{Na}$ segunda forma, a obtenção da sucata de cobre é feita por meio de centros de coleta de material reciclável que, em muitas vezes, estão contaminadas por óleo, tinta, plástico, solventes ou sais. O cobre obtido após o processo dessa segunda forma de reciclagem é considerado como Metal Secundário o qual, dependendo da nova aplicação pode não ter alto teor de pureza, porém, se for para a fabricação de fios e cabos elétricos, nos quais as impurezas no anodo devem ser insignificantes, a purificação deve ser realizada eletroliticamente.

Extração e concentração: Para a análise dessa etapa foram considerados os dados de uma empresa localizada no Distrito Cuprífero do Vale do Curaçá, em Jaguarari, estado da Bahia, onde é feita a extração do mineral em céu aberto. Essa empresa possui uma planta hidrometalúrgica para concentração e produção do catodo, a qual se localiza junto às instalações da empresa. A planta tem capacidade de produção de 5.000 toneladas por ano de catodo e destina-se ao tratamento das pilhas de minério oxidado ali existentes. A logística utilizada para o cálculo do consumo de diesel, que será um dos dados da entrada de energia, levará em conta apenas o concentrado produzido pela mineração, descartando o importado. O concentrado produzido é transportado pela Ferrovia Centro-Atlântica (FCA), quando procedente da Mineração Caraíba, ou por caminhão, quando é suprido por outra mina localizada no estado de Goiás ${ }^{20}$. No que diz respeito aos produtos metálicos da empresa, o principal meio de transporte é o rodoviário, em caminhão carreta, quer seja destinado ao parque consumidor doméstico, localizado, principalmente, em São Paulo e Rio de Janeiro, quer destinado ao mercado externo, cujo embarque em navios

14 | P á g i n a 
se dá, preferencialmente, no Porto de Salvador. Por não se ter dados para o cálculo de todas as rotas, a distância será baseada na rota para a fabricação de cabos utilizados em veículos, que parte de Dias D’Ávila (BA), onde se localiza a fundição e refino do cobre primário, com destino a Utinga (SP), onde são produzidos os arames dos quais são fabricadas peças e componentes para as indústrias automotivas. Todo transporte será baseado em caminhão carreta. Pela falta de dados disponíveis, o consumo de diesel interno na mina para a movimentação do estéril, será baseado em um consumo de diesel de uma mina de ferro, localizada na cidade de Congonhas-MG.

Produção do cobre primário: os dados de consumo para essa etapa foram obtidos do "Projeto Sul-americano de Avaliação do Ciclo de Vida dos Metais para uma Produção Sustentável - PROSUL", subgrupo do cobre, coordenado pela Universidade de Brasília (UnB), em parceria com a UFBA e o Centro de Investigação Minero Metalúrgica (CIMM) do Chile, são os únicos dados disponíveis no Brasil referentes a esse tipo de processo ${ }^{17}$.

Fabricação do cabo utilizado em automóveis: Por não ter conseguido dados de empresas do setor fabricante de cabo para automóveis, para auxílio desta pesquisa, utilizaram-se dados dos processos de fabricação, cedidos por uma empresa localizada na cidade de Divinópolis (MG), que fabrica fios e cabos elétricos utilizados no setor industrial e residencial. Essa empresa tem uma produção mensal de 450 toneladas de produtos acabados por mês, além de ser um centro de coleta de material reciclável contendo cobre.

Reciclagem de cabos obtidos da reciclagem de veículos: Os dados para avaliação dos impactos na etapa de reciclagem de cabos foram obtidos mediante pesquisas bibliográficas. Para a separação dos cabos do fio de cobre e impurezas, o equipamento tem uma capacidade média de produção de $1 \mathrm{t} / \mathrm{h}^{21}$. Na prensagem do cobre, utilizaramse os dados da pesquisa de Usinas termoeletricas ${ }^{22}$. Para o cálculo de transporte da sucata de cobre deve-se considerar que o centro de reciclagem de automóveis se localiza na cidade de Belo Horizonte (MG) e a reciclagem do cobre. Na cidade de Utinga (SP), citada no processo de extração e concentração.

\section{Análise do inventário}

Os dados do inventário de entrada de consumo de energia para cada processo foram coletados de acordo com $\mathrm{Reis}^{3}$, convertidos para $\mathrm{MWh} / \mathrm{tCu}$, unidade padrão definida neste artigo, e mostrados na (TABELA 2) conforme Reis ${ }^{3}$ :

TABELA 2: Resumo do consumo energético por processo.

\begin{tabular}{cccc}
\hline & & Recursos & \\
\hline \multirow{2}{*}{ Processos } & Energia Elétrica & Gás Natural \\
& $\mathrm{MWH} / \mathrm{tCu}$ & $\mathrm{MWH} / \mathrm{tCu}$ & Diesel \\
& 14420 & 15985 & $\mathrm{MWH} / \mathrm{tCu}$ \\
\hline 2 & 15500 & 0,0003 & 11355 \\
3 & 0,4220 & - & 0,0869 \\
4 & 0,1288 & - & 0,0868 \\
\hline
\end{tabular}

Os processos descritos na (TABELA 2) se referem à Figura 4 que trata dos limites do cenário com reciclagem, no ciclo de vida do cobre. Os dados foram calculados por Reis ${ }^{3}$, de acordo com as considerações feitas na definição do escopo para o ACV, as entradas no ACV são os tipos de energia utilizadas em cada processo para ser produzir 1 tonelada de cobre. 
Para o cenário com reciclagem, as somas dos recursos se limitam aos processos produção do cobre primário, fabricação do cabo utilizado em automóveis e reciclagem de cabos obtidos da reciclagem de veículos, pois já não há a necessidade da extração e concentração do minério de cobre, uma vez que essa matéria prima é obtida mediante processo de reciclagem de veículos.

\subsection{Avaliação dos impactos}

Após a definição do consumo energético, somouse o consumo de cada recurso utilizado em cada cenário definido no objetivo da ACV. O resumo dos consumos é mostrado na (TABELA 3) conforme estudo Reis ${ }^{3}$.

TABELA 3: Resumo dos consumos energéticos separados por cenário.

\begin{tabular}{|c|c|c|c|c|}
\hline \multirow{3}{*}{ Recurso } & \multicolumn{2}{|c|}{ Quantidade } & \multirow{2}{*}{$\begin{array}{c}\text { Diferença entre } 1^{\circ} \text { Cenário e } \\
2^{\circ} \text { Cenário }\end{array}$} & \multirow{2}{*}{ Economia } \\
\hline & $1^{\circ}$ Cenário & $2^{\circ}$ Cenário & & \\
\hline & $\mathrm{MWh} / \mathrm{tCu}$ & $\mathrm{MWh} / \mathrm{tCu}$ & $\mathrm{MWh} / \mathrm{tCu}$ & $\%$ \\
\hline Energia Elétrica & 3.4140 & 2.0508 & 1.3632 & 39,92 \\
\hline Gás Natural & 1.5988 & 0.0003 & 1.5985 & 99,98 \\
\hline Diesel & 1.2224 & 0.1737 & 1.0487 & 85,79 \\
\hline Total & 6.2352 & 2.2248 & 4.0104 & 64,31 \\
\hline
\end{tabular}

Vê-se na (TABELA 3) que há uma redução no consumo energético em todos os recursos, caso seja utilizado o $2^{\circ}$ cenário que é a obtenção do cobre a partir da reciclagem de veículos. A maior economia é do gás natural que é de $99,98 \%$, precedida do diesel com $85,79 \%$ e depois pela energia elétrica com $39,92 \%$. No geral, a economia no consumo dos recursos energéticos gerada pelo $2^{\circ}$ cenário é de $64,31 \%$. Os valores obtidos após a definição do consumo energético no objetivo da ACV são apresentados na (TABELA 4).

TABELA 4: Resumo do consumo energético.

\begin{tabular}{|c|c|c|c|}
\hline Descrição & Valores & Unidades & Fonte \\
\hline Produção até 2030 & 140.000 .000 & unid/carro elétrico & JC Logistica $^{14}$ \\
\hline Consumo médio de cobre & 81 & $\mathrm{~kg} / \mathrm{carro}$ & Castro $^{17}$ \\
\hline \multirow{2}{*}{ Consumo de cobre total } & 11.340 .000 .000 & $\operatorname{kg}($ cobre total $)$ & \\
\hline & 11.340 .000 & ton(cobre total) & \\
\hline Economia de energia com reciclagem & 4,01 & $\mathrm{MWh} /$ ton & Reis $^{3}$ \\
\hline Economia de energia total & 45.473 .400 & MWh & \\
\hline Diferença entre períodos (2030-2017) & 13 & anos de produção & \\
\hline Estimativa de Economia média por ano & 3.497 .954 & MWh/ano & \\
\hline Quantidade de horas/ano & 8.640 & horas & \\
\hline Economia de Energia & 405 & MW & \\
\hline Usina Termoelétrica de Araucária & 410 & MW & $\begin{array}{c}\text { Usina } \\
\text { Termoeletrica }\end{array}$ \\
\hline
\end{tabular}


A frota de automóveis elétricos chegará, em 2030, a 140 milhões de unidades ${ }^{6}$, considerando que o conteúdo de cobre de cada automóvel é de $81 \mathrm{~kg}$, isso totaliza um consumo de 11.340.000 toneladas ${ }^{17}$. Caso o cobre utilizado na fabricação dos veículos elétricos for de origem reciclável, a economia de energia será de 4,01 MWh/ton de cobre ${ }^{5}$, totalizando 45.473.400 MWh em 13 anos de produção que dá uma economia de 3.497.954 MWh/ano. Que, se dividir pelas quantidades de horas no ano, a economia instantânea será de 405 MW que equivale aproximadamente à geração de energia elétrica da usina Termoelétrica de Araucária que é 410 MW, considerada uma das maiores do Brasil $^{22}$.

Após os resultados, vê-se a aplicação da estrutura de análise do ciclo de vida, demonstrada na (FIGURA 1), com a definição do escopo da ACV para imputação dos dados, a análise do inventário de acordo com os consumos dos tipos de energia para a produção do cobre e seus impactos ambientais energéticos e validando a economia que se pode ter na utilização da reciclagem do cobre para a fabricação do carro do elétrico.

\section{Conclusão}

O objetivo proposto neste estudo foi atingido, pois os resultados observados mostram que a reciclagem do cobre nos veículos elétricos pode atingir uma economia média de 3.497.954 de MWh/ano, o equivalente à capacidade produtiva de energia elétrica de uma usina termoelétrica de grande porte no Brasil. Porém o presente trabalho demonstrou apenas as vantagens energéticas com o uso do cobre reciclado, a partir da reciclagem de veículos na fabricação de automóveis elétricos, devendo haver trabalhos futuros para demonstrar a viabilidade energética da reciclagem de outros minerais, principalmente os utilizados na fabricação de baterias, justificando a importância da reciclagem na sustentabilidade de carros elétricos.

\section{Declaração de conflitos de interesse}

Os autores do artigo afirmam que não houve nenhuma situação de conflito de interesse, tais como propostas de financiamento, emissão de pareceres, promoções ou participação em comitês consultivos ou diretivos, entre outras, que pudessem influenciar no desenvolvimento do trabalho.

\section{Referências}

1. BARAN, R. A Introdução de veículos elétricos no Brasil: avaliação do impacto no consumo de gasolina e eletricidade. 2012.139f. Tese (Doutorado em Planejamento Energético). Programa de Planejamento Energético da UFRJ. Disponível: <http://www.ppe.ufrj.br/ppe/production/tesis/baran.p df.> Acesso: 09 de abril de 2018.

2. SATO, P. Como funcionam os carros elétricos? Relatório técnico, 2009. Disponível em: <https:novaescola.org.br/conteudo/1088/comofuncionam-os-carros-eletricos>. Acesso em: 09 de abril de 2018.

3. REIS, P. E. Análise do ciclo de vida do cobre no processo de reciclagem de veículos. Dissertação. Programa de pós-graduação em Engenharia da Energia. Belo Horizonte, 2015.

4. FGV Energia. Caderno de carros elétricos 2017. Disponível em: <http://fgvenergia.fgv.br/publicacao/caderno-decarros-eletricos.> Acesso em: 08 de abril de 2018.

5. ORRICO, M.V.M. Otimização do dimensionamento de um sistema de motor elétrico e bateria para veículo elétrico. 2013.102f.Monografia (Graduação em Engenharia de Controle e Automação). Faculdade de Tecnologia. Universidade de Brasília. Brasília/DF. 2013. Disponível em: <http://bdm.unb.br/handle/10483/8232>. Acesso: 07/04/2018

6. SOCIETY OF ENVIRONMENTAL TOXICOLOGY AND CHEMISTRY - SETAC. Guidelines for lifecycle assessment: a code of practice. Bruxelas, 1993. Disponível em: <https://link.springer.com/article/10.1007/BF029788 97>. Acesso em: 08 de abril de 2018.

7. REIS, P.E; SILVA, F. N; CASTRO, E. D; SILVEIRA, J. R. Análise do ciclo de vida do cobre em um processo de reciclagem de veículos sobre a ótica de uma mobilidade inteligente. Anais de Congresso SAE Brasil, São Paulo, nov. 2017.

8. ISO 14040 ASSOCIAÇÃO BRASILEIRA DE NORMAS TÉCNICAS. NBR ISO 14040: Gestão ambiental - avaliação do ciclo de vida - princípios e estrutura. Rio de Janeiro: ABNT, 2009.

9. RIBEIRO, J.A.S. Cobre. Sumário Mineral, Salvador. Departamento Nacional de Produção Mineral-DPNM 2014. Disponível em: <http://www.dnpm.gov.br/dnpm/sumarios/sumariomineral-2015 >. Acesso em 06 abril de 2018. 
10. SILVA, A.G.G. Cadeia Produtiva do Cobre, 2011. 89 f. Trabalho de Conclusão de Curso (Especialização em Engenharia de Recursos Minerais) - Escola de Engenharia, UFMG, Belo Horizonte, 2011.

11. ESPINOZA, L.A.T.; GLOSER, S.; SOULIER, M. Dynamic Analysis of Global Copper Flows. Global Stocks, Postconsumer Material Flows, Recycling Indicators, and Uncertainty Evaluation. Environmental Science \& Technology, Karlsruhe, Germany, v 47, p.6564-6572, 2013. Disponível em: $<$ dx.doi.org/10.1021/es400069b|>. Acesso em 06 de abril de 2018.

12. Carros elétricos no Brasil. Banco de dados. Disponível em: <http://tecnologia.ig.com.br/201804-17/carros-eletricos-brasil.html. Acesso em: 06 julho de 2018.

13. Uso de cobre em veículos elétricos. Banco de dados. Disponível em: $<$ https://www.e3seriescenter.com/blog-engenhariaeletrica-moderna/uso-de-cobre-em-veiculoseletricos-e-hibridos>. Acesso em 06 de julho de 2018.

14. JC Logística. Montadoras se rendem ao carro elétrico. Banco de dados. Disponível em <http://jcrs.uol.com.br/_conteudo/2017/09/cadernos/ jc_logistica/587053-montadoras-se-rendem-aocarro-eletrico.html>. Acesso em: 06 de abril de 2018.

15. INTERNATIONAL COPPER STUDY GROUP. The World Copper Factbook 2013. Lisboa, Portugal: ICSG, 2013.

16. Indústria do cobre potencializa veículos elétricos. Banco de dados. Disponível em: http://procobre.org/pt/noticias/industria-do-cobrepotencializa-veiculos-eletricos/>. Acesso em $02 \mathrm{de}$ abril de 2018

17. CASTRO, D.E.; SOUZA, V. L. M.; BOVOLENTA, A. G. Reciclagem \& Sustentabilidade na indústria automobilística, ISBN: 978-85-913373-0-9, $1^{\text {a }}$ edição, Belo Horizonte: [ s.n.], 2012.

18. LIMA, A. M. F. et al: Avaliação do ciclo de vida (ACV): Estudo de casos de projetos cooperativos. Salvador: COBESA, 26 slides: color, 2010.

19. FARIAS, J. O. G. de. Produto 37 Cadeia do Cobre. Relatório Técnico 63 - Perfil do Cobre, ago. 2009.

20. MG RECYLCING, Compact 380 VZT, Banco de dados: Disponível em: $<$ http://www.mgrecycling.it/mgmach/4/compact380-vzt.html>. Acesso em: 08 mai. 2018

21. ABILITY, Prensas enfardadeiras e equipamentos para reciclagem, prensas enfardadeiras jacaré $p /$ metais. Manual técnico. Disponível em: <http://www.enfardadeira.com/enfardadeiras_jacare. html>. Acesso em: 08 de abril de 2018

22. Usinas Termoelétricas. Banco de dados. Disponível em:

<https://www.suapesquisa.com/energia/usinas_term oeletricas.htm>. Acesso em 02 de abril de 2018. 